\title{
A educação de surdos no Brasil no século XIX e - legado de países europeus
}

\author{
Cássia Geciauskas Sofiato \\ Universidade de São Paulo (Brasil) \\ Paulo Vaz de Carvalho \\ Universidade Católica Portuguesa (Portugal) \\ Orquídea Coelho \\ Universidade do Porto (Portugal)
}

\section{Resumo}

A educação de surdos teve início em muitos países a partir do século XIX por meio da influência do Instituto Nacional de Surdos de Paris, fundado no século XVIII. Foi o caso do Brasil com a fundação do Imperial Instituto dos Surdos-Mudos, em 1857, no Rio de Janeiro. Outro país que inaugurou esse tipo de educação no mesmo século foi Portugal, porém com outra linhagem, a sueca. Assim sendo, este estudo objetiva destacar as possíveis apropriações que o Imperial Instituto dos Surdos-Mudos do Brasil fez do Instituto Nacional de Surdos de Paris e do Real Instituto de Surdos-Mudos e Cegos de Lisboa, em relação à proposta pedagógica e trabalho de reabilitação. A pesquisa possui uma abordagem qualitativa e é do tipo documental e bibliográfica. $\bigcirc$ estudo possibilitou compreender que o instituto brasileiro assimilou vários aspectos do legado europeu, entre eles elementos do currículo e formação profissional para os alunos surdos.

Palavras-chave: Educação de surdos. Surdo. História da educação. Império no Brasil.

\section{Deaf people education in Brazil in the 19th century and the legacy of European countries}

\section{Abstract}

The education of the deaf people began in many countries from the 19th century through the influence of the National Institute for the Deaf People in Paris, founded in the 18th century. This was the case in Brazil with the foundation of the Imperial Institute of the Deaf-Mute People, in 1857, in Rio de Janeiro. Another country that inaugurated this type of education in the same century was Portugal, but with another lineage, the Swedish. Therefore, this study aims to highlight the possible influences that the Imperial Institute of the Deaf-Mute People of Brazil received from the National Institute of the Deaf People in Paris and the Royal Institute of the Deaf and Blind People of Lisbon in relation to the pedagogical proposal and rehabilitation work. The research has a qualitative approach and is documentary and bibliographic type. The study made it possible to understand that the Brazilian institute assimilated several aspects of the European legacy, including elements of curriculum and professional formation for deaf students.

Keywords: Deaf people education. Deaf people. Education history. Empire in Brazil. 


\section{La educación de los sordos en Brasil en el siglo XIX y el legado de los países europeos}

\section{Resumen}

La educación de los sordos comenzó en muchos países a partir del siglo XIX gracias a la influencia del Instituto Nacional para Sordos de París, fundado en el siglo XVIII. Este fue el caso de Brasil con la fundación del Instituto Imperial de Sordomudos, en 1857, en Rio de Janeiro. Otro país que inauguró ese tipo de educación en el mismo siglo fue Portugal, pero con otro linaje, el sueco. Así pues, este estudio tiene como objetivo poner de relieve las posibles apropiaciones que el Instituto Imperial de Sordomudos de Brasil hizo al Instituto Nacional del Sordo de París y al Real Instituto del Sordo-Mudo de Sordomudos y Ciegos de Lisboa, en relación con la propuesta pedagógica y el trabajo de rehabilitación. La investigación tiene un enfoque cualitativo y es de tipo documental y bibliográfica. El estudio permitió comprender que el instituto brasileño asimiló varios aspectos del legado europeo, entre ellos elementos del plan de estudios y de la formación profesional de los estudiantes sordos.

Palabras clave: Educación para sordos. Sordo. Historia de la educación. Imperio en Brasil.

\section{Introdução}

O século XIX no Brasil foi palco de uma série de transformações relevantes em função da conjuntura política, econômica, social e cultural da época. Com a proclamação da Independência do Brasil em 1822, afastar-se politicamente de Portugal e aproximar-se de modelos econômicos e culturais impressos pela Inglaterra e França tornou-se um objetivo (GONDRA, 2004). De acordo com o autor, no período entre 1822 e 1889, o Estado Imperial foi se consolidando como um projeto de Estado nacional. No referido período, houve a "[...] Independência, o Primeiro Reinado, o Período Regencial e, finalmente, a administração central de mais longa duração de nossa história - o reinado de D. Pedro II" (GONDRA, 2004, p. 21).

A configuração do Estado imperial também exigia um novo delineamento urbano e social, tendo em vista a sede do Estado e a necessidade de transformações de diversas naturezas:

De infra-estrutura urbana lágua, iluminação e esgotamento sanitário, por exemplo), transporte (arruamentos, carruagens, bondes e trens, dentre outros), economia (instalação de fábricas e de 
estabelecimentos comerciais), política (organização de partidos e sistema eleitoral), comunicação (imprensa, correios e telégrafos), segurança (guarda nacional, polícia e sistema judiciário) e cultural (biblioteca, jardim botânico, escola de belas-artes, faculdades, escolas de primeiras letras e secundárias) (GONDRA, 2004, p. 201.

Percebe-se que, dentro do âmbito cultural, a educação estava arrolada e várias iniciativas foram empreendidas no século em questão, mas com grandes desafios associados (SAVIANI, 2014; ARANHA, 1996). Desde meados do século XIX, Schueler (1999) destaca que a educação de crianças, assim como de jovens e adultos das camadas populares livres, nacionais, estrangeiras e libertas, foi incluída no âmbito das reformas do Estado imperial. A construção de escolas públicas e colégios expunha a ênfase na instrução e educação popular e o desenvolvimento da escolarização, paralelamente aos incrementos de outras ordens relativas à vida urbana. A autora ainda salienta que a partir dos anos de 1850 :

No âmbito da Corte imperial e posteriormente nas Províncias, intensificaram-se as preocupações e medidas em prol da implantação de um sistema de educação pública. Garantida como um direito dos cidadãos, desde a Constituição outorgada em 1824, a difusão da instrução primária emergiu como uma das primeiras iniciativas do Estado dirigidas às crianças e jovens (SCHUELER, 1999).

Por meio do Decreto n 1.331-A, de 1854, houve a aprovação do Regulamento para a reforma do ensino primario e secundario do Municipio da Côrte. Assim sendo, segundo Schueler (1999), foi determinado o público para o ensino primário e secundário. Tal decreto apresentava em seus capítulos aspectos relativos à instrução pública primária e secundária, à inspeção das escolas, às condições para o magistério público e regime das escolas públicas, além de outros detalhamentos relativos a esse expediente.

É interessante notar que, apesar de ser um Decreto que legitimava o acesso da população livre, vacinada e sem moléstias contagiosas às escolas, uma parcela da população não aparecia representada nas letras da lei: "[...] os cegos, os surdos-mudos e os aleijados" (IBGE, 1872, p. 5). 
Até a década de 1850, percebe-se que nada de efetivo em termos de instrução foi feito em relação a tais grupos não representados. Esse fato encontra uma justificativa, à época, se tomarmos como referência a Constituição de 1824 que previa a suspensão do exercício dos direitos políticos no título 2, artigo 8 "I. Por incapacidade physica, ou moral". Diante desse panorama legal que, a rigor, não reconhecia a necessidade de instrução para a referida população, no ano de 1854, foi fundada a primeira instituição especializada para um dos públicos supra mencionados: os cegos. O Imperial Instituto dos Meninos Cegos, fundado no Rio de Janeiro, preconizou as iniciativas de educação especializada no país e parece ter mobilizado outras, tais como a fundação do Imperial Instituto dos Surdos-Mudos, três anos mais tarde, objeto da pesquisa em questão.

A historiografia sobre o início da educação de surdos no Brasil é unânime em destacar o papel de Édouard Huet Merlo (1822-1882) como o responsável por apresentar, em 1855, ao Imperador D. Pedro II um projeto de educação para surdos na cidade do Rio de Janeiro, por meio de uma missiva (FONSECA [entre 2000 e 2010]; ROCHA, 2007). Tal projeto foi viabilizado em 1856 por meio da criação do Collegio Nacional para Surdos-Mudos de 4 Ambos os Sexos que tinha como diretores Édouard Huet Merlo, a Madame de Vassimon e suas filhas. A escolha dos referidos gestores foi feita pelo imperador. Efetivamente, após um ano de trabalho e solicitações de auxílio financeiro por parte de Édouard Huet Merlo e da comissão diretora que foi instituída, D. Pedro II oficializou uma subvenção e a instituição mudou de sede e de nome, passando a ser denominada Instituto Imperial dos Surdos-Mudos. Segundo Fonseca (200-2), o nome foi alterado para Imperial Instituto dos Surdos-Mudos em 1858.

Para que o Imperial Instituto dos Surdos-Mudos pudesse funcionar, precisou ser implementada uma estrutura administrativa e pedagógica em função, principalmente, de dois aspectos: tratava- se de uma instituição especializada para o trabalho com alunos surdos e estava subordinada, segundo Fonseca (200-2), à Inspetoria Geral da Instrução Primária e Secundária do Município da Corte. A referida inspetoria estava prevista no Regulamento para o ensino primário e secundário do Município da Corte, criado por meio do Decreto $n^{\circ} 1.331 \mathrm{~A}$, de 17 de fevereiro de 1854, já mencionado neste estudo. De acordo com a autora, tal inspetoria tinha como função: "[...] inspecionar escolas, colégios, estabelecimentos de instrução primária e secundária, públicos 
e particulares" (FONSECA 200-2). Importa destacar que o fato de o Imperial Instituto dos Surdos-Mudos estar sob a responsabilidade de tal inspetoria à época já se caracterizava como um diferencial, em função do caráter asilar atribuído a instituições de igual natureza em outros países. Nesse caso, as atividades da instituição em questão seriam acompanhadas por um órgão da Corte.

No campo historiográfico, também encontramos produções brasileiras, tais como: Sofiato (2018); Rocha (2007); Souza (2008); Silva e Castanha (2015) e Fonseca (200-2), entre outros, que destacam aspectos relacionados ao funcionamento do Imperial Instituto dos Surdos-Mudos em termos de gestão e desenvolvimento de uma proposta pedagógica. Entretanto, pode-se afirmar que o campo ainda se encontra aberto para novas pesquisas e aprofundamentos no que tange a aspectos escolares, suas especificidades e impactos ou espelhamentos constituídos a partir de experiências de outros países. Assim sendo, este estudo objetiva destacar as possíveis apropriações que o Imperial Instituto dos Surdos-Mudos fez de dois institutos europeus para a educação de surdos, em relação à proposta pedagógica e trabalho de reabilitação. Ademais, com base nas possíveis assimilações, destacaremos as singularidades e as repetições, tendo em vista a perspectiva de construção de conjuntos comparáveis (DETTIENE, 2004).

Trata-se de um estudo cuja abordagem é qualitativa, de natureza documental e bibliográfica (Gil, 2020). Muitos foram os institutos educacionais europeus que se dedicaram ao trabalho com alunos surdos a partir do século XVIII. Dentro das delimitações necessárias para a viabilização da pesquisa, optamos por utilizar como referências dois institutos europeus tradicionais na educação de surdos, a saber: o Instituto Nacional de Surdos de Paris, na França, e o Real Instituto de Surdos- Mudos e Cegos, em Portugal.

Os critérios para a seleção de tais países e institutos dizem respeito a quatro aspectos: i) o início da educação de surdos em séculos anteriores e, quando no mesmo século, décadas antes: França (século XVIII) e Portugal (século XIX); ii) a quantidade de produções acadêmicas sobre a educação de surdos em tais países; iii) as supostas influências diretas advindas da França e indiretas de Portugal; iv) a ausência de estudos de tal natureza. Para atendermos aos objetivos da pesquisa estabelecemos recortes temporais a fim de melhor dimensionar o objeto de estudo. Destarte, elegemos os seguintes períodos para cada país: os séculos XVIII e XIX (França), de 1823 a 1860 (Portugal) 
e de 1856 a 1892 para a educação de surdos no Brasil. Tais períodos foram selecionados em função da projeção das atividades pedagógicas e de reabilitação desenvolvidas pelos institutos em questão.

Fez parte do corpus selecionado para a análise, fontes de origem primária, compostas por relatórios dos ministros e secretários dos negócios do Império do Brasil, relatórios dos diretores do Imperial Instituto de SurdosMudos, documentos do Instituto Nacional de Surdos de Paris, do Real Instituto de Surdos- Mudos e Cegos. Para a análise das fontes, recorreu-se as contribuições de Marson (1984) no que tange a indagação aos documentos:

Sobre a existência em si do documento [...] o que é capaz de nos dizer, como podemos recuperar o sentido deste seu dizer, [...] quem o fez, em que circunstâncias e para que finalidade foi feito? sobre o significado do documento como objeto [...] como e por quem foi produzido? [...] para que e para quem se fez essa produção? ... e sobre o significado do documento como sujeito /por quem fala o documento? De que história particular participou? Que ação e que pensamento estão contidos em seu significado?) [...] em que consiste seu ato de poder? (MARSON, 1984, p. 52).

contato com fontes diversas e de natureza primária fez com que pudéssemos abrir novas possibilidades para pensar a educação de surdos no Brasil a partir do legado europeu. Ressignificar algumas questões que circulam pelo campo e trazer novas perspectivas para o campo historiográfico foi algo que almejamos nesta incursão histórica secular.

\section{Os primeiros institutos de educação de surdos da França e de Portugal}

\section{1 . O caso da França}

A fundação de institutos ou escolas especializadas acompanhou a iniciativa dos precursores da educação de surdos e se espalhou para outros continentes, além da Europa. Entretanto, pode-se dizer que Paris, por meio do abade Michel Charles de l'Épée, houve uma diferenciação do trabalho com a fundação da primeira escola pública para surdos, a perspectiva coletiva de 
trabalho e as sessões públicas para a demonstração do método utilizado, promovidas pelo referido sacerdote.

O abade l' Épée fundou a Instituição Nacional de Surdos Mudos em 1771, "com seus próprios meios", segundo Carvalho (2013). Essa decisão foi fruto de uma experiência de educação com duas gêmeas surdas que estavam sob a tutela de outro religioso que veio a falecer, o padre Vanin.

O seu contato com as duas meninas surdas convenceu o abade de que era possível ensinar os surdos através do uso de gestos e, a partir daí, propôs-se abrir uma instituição para receber outras crianças surdas e instruílas na religião (CARVALHO, 2013, p. 17).

Tal instituição funcionava em sua casa e tinha um número considerável de crianças surdas, de classes sociais distintas. Mais tarde, essa instituição se tornaria o Instituto de Surdos Mudos de Paris, que se tornou uma referência em nível mundial, pois foi o "[...] ponto de partida e a inspiração para muitas outras que surgiram quer em França quer por toda a Europa, fundadas por discípulos seus" (COELHO; CABRAL; GOMES, 2004, p. 163).

Com base na metodologia do abade L'Épée, avanços foram observados e a língua utilizada pelos surdos foi valorizada em seu processo pedagógico, além do uso da linguagem visual:

Ensinar surdos é menos difícil do que normalmente se supõe. Apenas temos que introduzir nas suas mentes através dos olhos o que tem sido introduzido nas nossas próprias mentes através dos ouvidos (CARVALHO, 2013, p. 19 APUD L'ÉPÉE, 1784).

Todo o processo acabou por formar surdos que se tornaram intelectuais e ganharam notoriedade em Paris (CARVALHO, 2013). Com a morte do abade L'Épée em 1789, uma figura politicamente polêmica o sucedeu, o abade Roch-Ambroise Cucurron Sicard que foi responsável pelo aperfeiçoamento do método criado pelo seu antecessor. Além disso, o abade Sicard, ao longo de parte de sua vida dedicada aos surdos, continuou promovendo as sessões públicas para a divulgação do trabalho realizado e publicou vários livros relacionados à educação de surdos.

Berthier (1874; 2013), em seu livro biográfico sobre o abade Sicard, apresenta especificidades de seu trabalho. Além de trazer reflexões acerca do 
A educação de surdos no Brasil no século XIX e o legado de países europeus

desenvolvimento linguístico dos surdos com base nos manuais didáticos elaborados pelo referido abade à época, o livro presenteia-nos com alguns detalhes sobre a sua inserção nesse campo. $\bigcirc$ abade Sicard não era um conhecedor fluente da língua dos surdos, sabia alguns sinais, ou gestos metódicos, e a datilologia. Os exercícios mensais que promovia abarcavam o público externo e reunia pessoas reconhecidas na sociedade e de outros países. A sala em que atuava contava com vários equipamentos. Nesse espaço, junto ao seu aluno Jean Massieu, performava com determinado estilo e cativava o público que, por vezes, possuía um interesse natural pelo fenômeno deficiência. Os cursos que promovia tinham um público seleto e recomendado, apesar das críticas que, eventualmente, também recebia.

abade Sicard faleceu em 1822 e deixou um legado reconhecido para a posteridade e constructos que alicerçaram a educação de surdos à época. Berthier (1874; 2013 , p. 95) aponta que, depois da morte do abade Sicard, "[...] o ensino foi largado ao abandono sem garantia ou controlo e, cada professor constituía um sistema particular à sua vontade". Assim sendo, teve fim o império dos abades e a gestão da instituição passou para as mãos de leigos.

Após a morte do abade Sicard, o instituto passou a ser administrado por Joseph-Marie de Gérando, apoiador do oralismo. Marcada por uma diferente concepção de educação de surdos, sua gestão foi conturbada, reconhecida pela presença de nepotismo no Instituto, afastamento dos professores surdos, tentativas de banimento da língua de sinais ou gestual e inserção de diretores que não tinham conhecimento sobre a surdez e suas implicações. Consequentemente, a qualidade do ensino foi afetada, ainda mais por um sistema instaurado de rotatividade de professores que priorizava a leitura labial e ensino da fala. Tais aspectos geraram uma grande insatisfação entre pessoas do meio, notadamente, de alguns professores do Instituto e apoiadores ouvintes (CARVALHO, 201 1). Faz-se necessário destacar o papel de alguns opositores a esse tipo de gestão e posicionamento, entre eles, Ferdinand Berthier e RochAmbroise Auguste Bébian, que eram defensores da língua de sinais ou gestual na educação de surdos e que lutaram em prol do resgate do trabalho com tal língua no Instituto.

Como uma forma de reação à investida oralista no Instituto, para além dos muros da instituição, houve a organização de uma série de banquetes dos surdos-mudos. Os referidos banquetes, liderados por Ferdinand Berthier e 
alguns colegas, tinham como uma primeira motivação a celebração do nascimento do abade l'Épée, mas, por certo, também tinham outras intenções:

Em 1834, 122 anos após o nascimento do abade de l'Épée e época do declínio de sua obra, Ferdinand Berthier (1803-1886), professor surdo da Instituição de Paris, juntamente com alguns de seus colegas surdos, como Alphonse Lenoir e Claudius Forestier, resolvem criar um Comitê de surdos-mudos. A primeira decisão desse comitê, na sessão de 15 de novembro de 1834, é a de organizar banquetes anuais para celebrar o nascimento do 'pai dos surdosmudos': 'esse evento único foi uma grande revolução para o povo surdo-mudo'. [...] Os banquetes dos surdos-mudos, mobilizações contra os riscos que corria a língua de sinais, tinham na verdade uma função eminentemente políitica e usavam como pretexto a homenagem ao abade. Os banquetes representam um lugar de resistência à dominação da ideologia oralista e consequente criação de um espaço novo dentro da própria comunidade surda (BENVENUTO; SÉGUILLÓN, 2016, p. 64).

Segundo Benvenuto e Séguillon (2016), houve a dominação do oralismo no final do século XIX na França em função do conhecido Congresso de Milão, em 1880. Sem a pretensão de alongar a discussão sobre tal congresso, pois não é o foco deste estudo, reconhecemos que o Instituto Nacional de Surdos de Paris também foi alvo das decisões acordadas no evento: "Viva a fala", apesar das resistências e do movimento surdo.

Vimos por meio desta incursão sobre a educação de surdos na França que o Instituto Nacional de Surdos de Paris contribuiu por meio de sua expertise com a fundação de outras instituições, em diferentes partes do mundo. Entretanto, a educação de surdos em Portugal principiou com base em outra linhagem: a sueca.

\section{2. O caso de Portugal}

A educação de surdos começou a ser pensada em Portugal após 1820, de acordo com Ribeiro (2018, p. 61), com a Declaração dos Direitos do Homem e do Cidadão e a Constituição Portuguesa, de 1822. A referida Constituição abarcava princípios que intrinsecamente "[...] conduziam a uma aceitação de todos os que eram diferentes, mas iguais perante a lei". Segunda 
A educação de surdos no Brasil no século XIX e o legado de países europeus

a autora, houve tentativas de implementar esse ramo de ensino ao nível de Estado por parte de alguns professores, entre eles, João Antônio de Freitas Rego, Antônio Patrício, Lucas Maria Xavier Leal, aparentemente sem sucesso.

Em 1823, ocorreu uma mudança no cenário lusitano por conta de um convite feito por D. João VI ao professor sueco Pedro Aron Borg. $\bigcirc$ convite era para fundar uma escola para surdos em Portugal nos moldes do instituto criado por ele em seu país. Essa iniciativa foi fruto de toda uma diligência diplomática portuguesa em busca de um professor com perfil para a educação de surdos e cegos (ALVES, 2012).

Pedro Aron Borg fundou em 1823 o Real Instituto de Surdos-Mudos e Cegos, em Lisboa, mas muitas questões sobre o surgimento da referida instituição ainda se encontravam sobre a mesa, esperando uma melhor definição e adensamento em termos historiográficos, segundo Carvalho (2019).

Inicialmente, a instituição foi financiada pelo próprio rei, entretanto, quem assumiu a responsabilidade administrativa foi a Real Casa Pia de Lisboa. Alves (2012), em seu estudo comenta que antes da fundação do Instituto específico para surdos, a Casa Pia se responsabilizava pela educação de crianças surdas e cegas, além da população infantil em situação de pobreza e miséria, que recebia dotação orçamentária para isso. Apesar da administração ser de responsabilidade da Casa Pia, o Real Instituto de Surdos-Mudos e Cegos tinha autonomia em relação à gestão.

Desentendimentos entre Pedro Aron Borg e a administração da Real Casa Pia de Lisboa foram observados, relata Ribeiro (2018). Diante desse fato, o governo atendeu à solicitação de Pedro Aron Borg quanto à separação da Casa Pia. Para que o instituto pudesse se manter, o governo repassou uma dotação anual no valor de 4:600\$000 réis.

No ano de 1828, o professor sueco retornou ao seu país e não há um consenso sobre o motivo de sua saída de Portugal, uns alegam que foi em função de motivos políticos e outros, pessoais. Após a sua saída, João Hermano Borg, irmão do antigo diretor, assumiu a gestão e José Crispim da Cunha tornou-se seu ajudante. Ribeiro (2018) afirma que, a partir de 1828, o instituto foi alvo de "pressões e incompreensões". Segundo a autora, com a morte de João Borg em 1833, José Crispim assumiu a direção do estabelecimento e trabalhou demasiadamente para a sua reabilitação, porém, em 1834, o instituto voltaria 
a ser anexado à Casa Pia por determinação governamental, motivo que levou José Crispim da Cunha a abandonar o cargo.

A proposta pedagógica desenvolvida no Real Instituto de SurdosMudos e Cegos, no caso dos surdos, abarcava a educação intelectual e tecnológica (BORG, 1824). Ademais, assumiu aspectos peculiares advindos do perfil de seu fundador sueco:

Pedro Aron Borg era natural de um país nórdico, cuja religião professada era o luteranismo e adoptava um conjunto de estratégias particulares, quer no plano social, quer no plano educativo, onde as ideias de higienização da ciência médica se configuravam através da 'ordem, do asseio, da vacinação e da ginástica' e abrangiam uma educação especial. Este modelo de educação tinha por base um conjunto de tecnologias educativas específicas que promoviam a acessibilidade dos públicos diferenciados, não só ao currículo escolar, como também às aquisições e aos saberes técnico-profissionais (ALVES, 2012, p. 154).

Após a saída de José Crispim da Cunha, Ribeiro (2018, p. 66) menciona que a direção do Instituto ficou sob a responsabilidade de ex-alunos e de um empregado e os "[...] serviços não foram os mais brilhantes". Consequentemente, o trabalho não atingia os seus objetivos primeiros e, em 1844, a renda subsidiada pelo governo foi suspensa. Tal fato juntou-se às demais dificuldades, provocando a extinção dos trabalhos da instituição em 1860. Carvalho (2007) pondera que durante o período de 10 anos não se teve registro sobre os rumos da educação de surdos no país.

Com base em Martins (2020) e Ribeiro (2018), constata-se que o trabalho com surdos na capital foi retomado por meio da iniciativa do Padre Pedro Maria de Aguilar a partir de 1870. Tal sacerdote, ao estudar o ramo de ensino, criou uma aula gratuita no Liceu de Lisboa e posteriormente inaugurou uma escola própria em Guimarães em 1872. Carvalho (2007, p. 146) pontua que em 1887, "[...] a Câmara Municipal de Lisboa fundou o Instituto Municipal de Surdos-Mudos[...]". Eliseu Aguilar foi convidado para ser o diretor e, ao aceitar o convite, levou à extinção o Instituto de "surdos-mudos" do Porto, fundado pelo seu tio padre Pedro Maria Aguilar". Entretanto, em função de irregularidades constatadas, Eliseu Aguilar foi afastado e quem assumiu sua posição foi José Miranda de Barros, mas a direção do Instituto de SurdosMudos ficou a cargo do diretor dos asilos Municipais. Após a saída de José 
Miranda, em 1892, quem assumiu a direção do instituto foi João José Teixeira e o ensino de "surdos-mudos" entrou em decadência (CARVALHO, 2007).

O trabalho com surdos no final do século XIX em Portugal ganhou novos contornos com a abertura de outros institutos, além de Lisboa.

\section{A educação de surdos no Brasil e as influências europeias}

Após delinearmos a gênese dos dois institutos europeus selecionados para a pesquisa, trataremos da educação no Imperial Instituto dos SurdosMudos e os entrelaçamentos com as instituições europeias. Dessa forma, comparar as realidades não é o foco deste estudo, mas sim assinalar as repetições e singularidades na forma de educar surdos, considerando a proposta pedagógica e de reabilitação.

\subsection{Proposta pedagógica}

Iniciamos explicitando a proposta pedagógica do Imperial Instituto

12 dos Surdos-mudos, conforme consta em seu processo de fundação e ao final do século XIX:

Regenerar uma classe inteira de seres desgraçados muito tempo abandonados, pô-los na posse de uma instrucção impossível de adquirir de qualquer outro modo, por meio de um methodo especial, restitui-los a sociedade, à sua familia e pô-los em estado de poderem um dia dirigir os seus proprios negócios tal tem sido o fim do estabelecimento (ALMANAK LAEMMERT, 1857, p. 437).

[...]

Instituto dos Surdos-Mudos tem por fim ministrar-thes instrucção litteraria, educação moral e ensino profissional, o qual será regulado por instrucções especiaes organisadas pelo director e approvadas pelo commissario do governo (ALMANAK DOS AMIGOS DOS SURDOS-MUDOS, 1888, p. 8).

Embora a redação tenha sofrido alteração, a essência continuava a mesma, ou seja, instruir e profissionalizar os surdos eram os objetivos primordiais. Para tal, o curso completo oferecido teria a duração de seis anos e o estabelecimento funcionaria em regime de internato, inicialmente misto, atendia 
meninos e meninas. A partir de 1873 passou a atender somente meninos e o retorno das meninas só foi restabelecido no século XX.

Desde o princípio, o Instituto tinha como objetivo a instrução dos alunos surdos por meio do estabelecimento de um currículo prescrito, composto pela hibridização de disciplinas de nível elementar e de segunda classe propostas pelo Império, levando em consideração a surdez : "[...] escripta e leitura, elementos da língua nacional-grammatica, noções de religião e dos deveres sociaes, cathecismo, geographia, historia do Brasil, historia sagrada e profana, arithmetica, desenho e escripturação mercantil" (ALMANAK LAEMMERT, 1857, p. 437). Sofiato (2018) demonstra que, ao longo do século XIX, houve algumas alterações em relação ao currículo e algumas disciplinas deixaram de ter tanta ênfase no processo escolar. No final do século em questão, percebe-se que o maior empenho era dado às disciplinas de língua nacional, especificamente linguagem escripta, além de arithmetica para a aquisição de habilidades básicas pelos alunos surdos.

Além do currículo, reconhecia-se a vertente especializada do estabelecimento com base no uso de métodos e lições específicas para o trabalho com surdos e a assimilação de métodos em vigor na educação comum, tais como o intuitivo (LEITE, 1870).

Ademais, havia a intenção de restituir os surdos à sociedade por meio do aprendizado de um ofício e, para isso, eram oferecidas algumas oficinas com o teor profissionalizante, tais como horticultura, sapataria, marcenaria, alfaiataria. Esse aspecto adquire mais força na gestão do Dr. Tobias Rabello Leite a partir de 1869 (SOFIATO, 2019). Apesar do caráter específico do Instituto e a tentativa de acompanhar a tendência geral da educação à época, o educar e civilizar eram a tônica do estabelecimento. Gondra (2004), pontua que esta dupla ação tinha um único fim:

Eliminar os fatores adversos e produzir um futuro novo, regenerado, sem vícios, grandioso para os indivíduos, para a sociedade e para o Estado... [...]. No entanto, esta finalidade só seria atingida caso a educação escolar funcionasse como um verdadeiro decalque do projeto construído em nome da racionalidade médico-higiênica. Assim planejado, medido, controlado, integrado e hierarquizado, esse modo de intervenção funcionaria como um efetivo programa civilizador, instituindo nos trópicos uma réplica complexa do que então era considerado como padrão civilizatório a ser 
disseminado, imposto e adotado no mundo ocidental (GONDRA, 2004, p. 22).

objetivo específico dos alunos surdos brasileiros, de acordo com o preceito da época era de "[...] organizar o Estado Nacional independente, moderno e civilizado" (GONDRA, 2004, p. 47). A regeneração era mais que justificada, pois tais alunos eram tidos como infelizes, infortunados, pertencentes em geral as classes desvalidas (OLIVEIRA, 1872) e oneravam a sociedade com a sua presença não produtiva. E, assim, se fazia e se propagavam os resultados nos exames públicos ao final de cada ano, com a presença do Imperador, considerado como um pai para os surdos, ou de seus familiares. Nesse caso, a educação ainda longe de ser considerada um direito para os alunos em questão, era promovida devido à "[...] irradiante bondade do Augusto Chefe da família brasileira" (ALMANAK DO AMIGO DOS SURDOS-MUDOS, 1888, p. 4). Isso ocorria apesar dos esforços do Dr. Tobias Rabello Leite, último gestor da época do Império, no sentido de oportunizar a educação para os surdos e reconhecê-la como de direito numa época em que o discurso da benevolência era o dominante e secular.

$14 \quad$ A incursão realizada nos institutos europeus selecionados evidenciou vários aspectos em comum em relação à finalidade dos estabelecimentos no século XIX, ou seja, aspectos que foram assimilados pelo Brasil por meio dos precursores neste tipo de trabalho. Vimos neste estudo que a trajetória educacional dos surdos na França teve início no século XVIII. Entretanto, formularemos as aproximações com base na proposta pedagógica e de reabilitação nos oitocentos, assim como em Portugal.

Deltour (1892) considerava o Instituto Nacional de Surdos de Paris um local de "educação intelectual, profissional e moral", apesar das dificuldades enfrentadas pela instituição em anos anteriores no que tange ao encaminhamento do trabalho pedagógico e suas implicações. Du Camp caracterizava como objetivo da instituição:

Por meio da educação escolar, iluminar inteligências que a natureza parece ter obscurecido, e treinar trabalhadores laboriosos e habilidosos que possam prover suas necessidades e nunca cair no comando da caridade pública (DU CAMP, 1873, p. 577, tradução nossa) . 
O curso tinha a duração completa de sete anos, mas reconheceu-se a necessidade de mais um ano. Segundo Leite (1868), o curso francês tinha três divisões: o elementar, do $1^{\circ}$ ao $4^{\circ}$ ano; o secundário, do $5^{\circ}$ ao $7^{\circ}$ ano e o superior.

De acordo com Deltour (1892, p. 22), seguindo o princípio filosófico cristão "[... invisibilia per visibilia intellecta conspiciuntur [...]", o professor usaria coisas e palavras conhecidas para explicar coisas e palavras desconhecidas. Para atingir a educação intelectual, o programa do Instituto de Paris seguia o seguinte percurso:

$1^{\circ}$ ano - Linguagem escripta, linguagem falada; $2^{\circ}$ ano -
Linguagem escripta, linguagem falada, sommar e diminuir; $3^{\circ}$
ano - Linguagem escripta, linguagem falada, historia sagrada,
multiplicar e repartir; $4^{\circ}$ ano - Linguagem escripta, linguagem
falada, historia sagrada, fraç̧ões; $5^{\circ}$ ano - Linguagem escripta,
linguagem falada, historia e geographia e decimaes; $6^{\circ}$ ano -
Linguagem escripta, linguagem falada, historia e geographia e
proporções; $7^{\circ}$ ano - Linguagem escripta, linguagem falada, his-
toria e geographia e complexos; superior - Grammatica franceza,
historia, geographia, arithmetica, álgebra, geometria e direito
comum (LEITE, 1868, p. A-D7-5).

No ano de 1868, o diretor Tobias Rabello Leite cotejou a matriz curricular do instituto francês com a do Imperial Instituto dos Surdos-Mudos do Brasil. Embora a França fosse a referência, notou que as matrizes curriculares apresentavam diferenças, a começar pelo tempo de duração dos cursos; o do Imperial Instituto dos Surdos-Mudos era menor. As disciplinas, em geral, eram semethantes, mas coloca-se como um limite para este estudo avaliar os conteúdos que eram ministrados. $\bigcirc$ instituto francês, segundo a ótica de Tobias Rabello Leite, investia no ensino da linguagem e percebia a necessidade do surdo se relacionar com a sociedade por seu intermédio. Grande parte do curso era dedicada ao trabalho com a linguagem na modalidade escrita e oral. Os demais conhecimentos, advindos de outras áreas, poderiam ser conquistados ao longo da escolaridade e serviam de estímulos para o trabalho linguístico. $\bigcirc$ ensino religioso também compunha o currículo.

Outrossim, no Instituto francês havia a formação profissional por meio do oferecimento de oficinas, a depender do gosto do aluno e de sua família. A concepção que pautava tal atividade levava em conta a possibilidade de 
oferecer ao alunado considerado pobre um meio de subsistência e um passatempo agradável ou preparação para a carreira artística ao rico. Algumas oficinas oferecidas pelo instituto francês eram as seguintes: escultura em madeira, tipografia, litografia, carpintaria, sapataria e horticultura (DELTOUR, 1892). Tal concepção de formação profissional foi assimilada pelo instituto brasileiro, ipsis verbis. De acordo com Gondra (2004, p. 107), no século XIX, a educação foi um "[...] objeto para o qual os médicos estenderam o seu discurso [...]" e a preocupação da escola voltava-se para a regeneração social. No caso também dos alunos surdos percebe-se esse viés, tanto na formação acadêmica quanto na profissional. Assim sendo, os surdos deveriam desempenhar o papel sociai delineado em função de sua condição específica depois de concluírem os seus cursos, atendendo à demanda de mão de obra para o país.

Em Portugal, que iniciou a educação de surdos 33 anos antes do Brasil e cuja linhagem era sueca, observamos que a intencionalidade da educação também era similar e, como nos demais casos, previa a formação profissional:

O objecto deste Estabelecimento será de preparar um futuro mais venturoso a estes entes desvalidos da natureza, pelo desenvolvimento, e formação de suas faculdades intelectuais; e a proporcionar-thes aqueles conhecimentos, e perfeição em algum ofício mecânico, manufactura, ou Arte, segundo as ideias e propensões de cada um que possam pelo em diante proverem a sua subsistência, e deste modo tornarem-se também úteis à sociedade (BORG, 1823, p. 1).

Além do que foi pontuado, o que nos chama a atenção no excerto anterior é a forma de se referir aos alunos surdos como "entes desvalidos da natureza". Ao que parece, existiu por parte de Pedro Aron Borg certo cuidado ao tentar caracterizar tais pessoas e sua condição humana diferenciada. No Brasil, o discurso para se referir aos surdos nos documentos examinados é predominantemente marcado por adjetivações advindas da idade antiga e moderna, absolutamente arraigado na ideia de infortúnio.

$\bigcirc$ curso oferecido pelo instituto português era de oito anos, período superior ao do instituto brasileiro e francês. De acordo com Borg (1824), programa de educação lusitano comportava duas vertentes: a intelectual e 
a tecnológica. Posto isso, fazia parte da formação intelectual os seguintes aspectos:

Perceber, ler e de escrever ortograficamente a sua língua materna. Contar ao menos as quatro espécies, e a regra de três, tanto simples como em quebrados. Alunos das classes superiores: primeiras noções da pura matemática, noções elementares da História da sua pátria, na História Universal, Gramática da Língua Materna, nas ideias principais do Direito Natural, e da Moral, na História Sagrada e Doutrina Divina de Jesus Cristo (BORG, 1824, p. 6).

As disciplinas oferecidas também não se diferenciavam tanto das que eram propostas pelo instituto brasileiro, exceto no caso da geografia. No que tange à formação tecnológica, estava prescrito o debuxo, o desenho e a organização de oficinas para os alunos agraciados e, de acordo com cada ofício, seriam produzidas obras para a casa e em atendimento a encomendas externas. Cunha (1835) relata que as oficinas oferecidas eram as de alfaiataria, sapataria, carpintaria, marcenaria e funilaria.

O recurso proveniente de tal iniciativa verteria para o próprio estabelecimento, visando a captação de mais alunos. Ao verificarmos essa matriz de saberes percebemos certa similaridade com a matriz do instituto francês no que se refere ao ensino do direito natural, algo que não estava previsto no instituto brasileiro. Entretanto, em relação ao ensino profissional, o Imperial Instituto dos Surdos-Mudos do Brasil mantinha o mesmo procedimento quanto à produção de produtos para consumo interno dos alunos (LEITE, 1872) e atendimento às encomendas externas. Leite (1874) pontuava que as oficinas não tinham por objetivo produzir renda, mas sim formar artistas para aumentar a indústria nacional.

As oficinas oferecidas pelo Imperial Instituto dos Surdos-Mudos eram praticamente as mesmas oferecidas nos institutos europeus, excetuando-se algumas tais como funilaria. Diante disso, podemos dizer que até a proposta de formação profissional foi incorporada pelo instituto brasileiro. 


\section{2. Proposta de reabilitação}

$\bigcirc$ processo de reabilitação dos alunos surdos estava previsto e era intrínseco à proposta educativa dos institutos estudados no século XIX. Porém, cada instituto tinha o seu protocolo de atendimento especializado à época.

Imperial Instituto dos Surdos-Mudos do Brasil trabalhava à luz da abordagem oralista para os alunos que apresentassem "[...] aptidão para semelhantes exercícios" (ALMANAK LAEMMERT, 1856, p. 437). $\bigcirc$ trabalho previa lições de pronúncia, de articulação artificial e de leitura sobre os lábios.

Ao longo do século XIX alguns problemas, tais como a falta de professor, comprometeu o trabalho de linguagem articulada, especificamente, no final de tal século. Existem indícios de que uma língua de sinais circulava pelo instituto, mas à época não era considerada língua e, tampouco seu uso não estava previsto nas atividades acadêmicas (SOFIATO, 2018). Basicamente, no século XIX, o trabalho do instituto brasileiro esteve assentado no oralismo e isso se intensificou após o ano de 1880, com as repercussões do Congresso de Milão e a incidência no trabalho com a oralidade.

18 L'Épée, adotava o método mímico e todo o trabalho pedagógico se embasava por meio de tal proposta. Após a sua morte, o abade Roch-Ambroise Cucurron Sicard deu continuidade ao trabalho com tal método, mas, após a sua morte e ao longo do século XIX, houve uma mudança nos rumos da instituição e a presença de Jean Marc Gaspard Itard, médico francês, fortaleceu a medicalização no instituto. Por conseguinte, o trabalho com a oralidade ocupou um lugar cada vez mais amplo no currículo escolar (SÉGUILLON, 1995).

Deutour (1892) menciona que a partir de 1880, os alunos foram submetidos à instrução por meio da oralidade. Segundo Séguillon (1995), um novo currículo foi aprovado para o instituto francês em 1889 e nesta altura houve a formalização do método oral como único para o ensino dos surdos e a desmutização como fator de higiene para os alunos. As medidas a partir de 1880, segundo Virenque (2017), faziam parte de um contexto mais amplo, fundamentadas no higienismo e no discurso médico, ancorados no progresso científico. Nesse contexto, a língua francesa seria a língua única, não cabendo a presença de uma língua sinalizada, correspondendo aos ideais educacionais da terceira república. 
O Imperial Instituto de Surdos-Mudos, acabou assimilando as concepções francesas relativas ao trabalho de reabilitação dos alunos surdos e a perspectiva higienista estava presente no âmbito educacional, conforme assinala Gondra (2004).

Portugal imprimiu um percurso um pouco diferenciado em relação ao processo de reabilitação dos alunos surdos. Segundo Carvalho (2007), Pedro Aron Borg utilizava um método gestual para se comunicar com os alunos e um alfabeto manual. Também era dada ênfase à leitura e à escrita. Tal método combinado, foi mantido até a extinção do Instituto em 1860. De acordo com o autor, o ensino da articulação e da leitura labial era muito restrito.

Carvalho (2007) ainda pondera que o padre Pedro Maria Aguilar usava uma metodologia baseada na "mímica e na linguagem escrita" com seus alunos quando o trabalho com surdos foi retomado após a extinção do Real Instituto para Surdos-Mudos e Cegos.

No Instituto Municipal de Surdos, que não é foco deste estudo, uma mudança de proposta ocorreu entre os anos de 1891 e 1892 com o professor José Miranda de Barros que começou a utilizar os métodos oralistas, com a articulação da fala e leitura labial, com críticas à língua de sinais ou gestual. Em 1892, Eliseu Aguilar foi readmitido como professor no Instituto com uma nova mudança de método.

No século XIX, observamos que o trabalho ocorria com base na língua gestual ou de sinais no Real Instituto de Surdos-Mudos e Cegos de Portugal, além do investimento em outras frentes, tais como a leitura, a escrita e a oralidade. Tal cenário se assemelhava ao do instituto francês no século XVIII e em nada se parecia com o que ocorria no Brasil no século em questão.

\section{Considerações finais}

Ao longo do século XVIII e XIX, as práticas desenvolvidas no Instituto de Surdos Mudos de Paris se consolidaram e, como apontado anteriormente, alcançaram outros países e continentes. $O$ Instituto de Paris exerceu influência direta na educação de surdos do Brasil, pois Édouard Huet Merlo era francês e os gestores que atuaram após a sua saída mantiveram esta referência como a que deveria ser seguida, apesar das opções já existentes em outros locais do mundo. Portugal, apesar de ter iniciado a educação de surdos 
por meio da iniciativa e expertise de um professor sueco, também incorporou alguns elementos do modelo francês, e, consequentemente, apresentou alguns aspectos comuns ao Brasil no que tange à educação de surdos, apesar das questões políticas e rupturas existentes por ocasião da independência do Brasil em 1822. Tais aspectos diziam respeito a algumas disciplinas do currículo prescrito.

estudo evidenciou que a finalidade de criação dos institutos para surdos era semelhante nos três países e que o Brasil se apropriou de elementos de uma tradição europeia já estabelecida e, de certa forma, legitimada por meio de suas práticas e notoriedade. Importa salientar que, no caso da educação de surdos do Brasil, não percebemos nos oitocentos uma tendência por parte dos gestores do Imperial Instituto dos Surdos-Mudos de criar uma identidade nacional para tal iniciativa. Embora já existisse uma tendência de pensar a educação brasileira além da importação de valores culturais, segundo Martinez (1997), a ideia de transplantar para a educação de surdos brasileira os ideais europeus, com pequenas adaptações, era recorrente. Os intelectuais referendados pelos gestores brasileiros e os manuais adotados eram franceses (os últimos com a devida tradução para a língua portuguesa), a didática, os

20 materiais didáticos também eram importados da França, Alemanha e a forma de organizar e gerir a instituição também espelhavam a admiração à França. Tudo isso denota a tendência do instituto brasileiro em acompanhar os referenciais estrangeiros, considerados melhores, independentemente do contexto em que eram aplicados.

Não obstante tenha existido uma relação histórica intensa entre Brasil e Portugal, verificamos que as práticas desenvolvidas no instituto português não impactaram diretamente o Brasil. É curioso constatar que a anuência para que a educação de surdos tivesse início em Portugal veio por parte de D. João $\mathrm{Vl}$, que empreendeu uma série de modificações estruturais no Brasil na época em que era colônia. Quando regressou a Portugal, esta foi uma das primeiras inciativas em seu país de origem. A educação de surdos no Brasil só se efetivou muitos anos mais tarde com a anuência de seu neto e por intermédio de um estrangeiro envolvido com a causa

Independentemente das questões apontadas anteriormente, o estudo permitiu perceber que em alguns aspectos a educação de surdos dialogava com a educação comum oferecida no Brasil. A influência das leis educacionais do Império no modus operandi do instituto, a escolha da horticultura como uma 
das atividades fim, levando em consideração que o Brasil tinha uma economia agrícola, e o destino das crianças consideradas desvalidas e, nesse caso, ainda consideradas infelizes.

Consideramos que o Imperial Instituto dos Surdos-Mudos assumiu a razão higiênica no século XIX, liderada pela razão médica (GONDRA, 2004), igualmente aos institutos europeus estudados, apostando no poder do discurso médico centrado na regeneração do social. O discurso híbrido de caridade e civilidade motivava as ações empreendidas pelos educadores designados e confirmava o destino de cada surdo de acordo com a sua desenvoltura no processo educacional e de reabilitação.

A análise da trajetória do desenvolvimento da educação de surdos no Brasil nos oitocentos permitiu constatar que o período em questão foi essencial para que se estabelecessem os fundamentos desse tipo de educação, ainda que influências estrangeiras tenham sido bastante incisivas e determinantes. Em decorrência de tais aspectos, pode-se dizer que o Brasil constituiu uma tradição, marcada por desafios e conquistas, auferidas por muitos protagonistas envolvidos com a área.

\section{Notas}

presente trabalho foi realizado com o apoio da Coordenação de Aperfeiçoamento de Pessoal de Nível Superior- Brasil (CAPES) - Código de Financiamento 001.

1 Neste sentido, aulas de canto não eram oferecidas e não estavam previstas (MARTINEZ, 1997).

2 Do original: "Elle doit par l'enseignement scolaire éclairer des intelligences que la nature semblait avoir obscurcies, et former des ouvriers laborieux, adroits, qui puissent subvenir à leurs besoins et ne jamais tomber en charge à la charité publique".

3 Alunos não pagantes.

\section{Referências}

ALMANAK Laemmert (1844-1889). Center for research libraries. Global Resources Network, 1857. Disponível em: hitp://www-apps.crl.edu/brazil/almanak. Acesso em: 17 jun. 2018.

ALMANAK Laemmert (1844-1889). In: Center for Research Libraries. Global Resources Network, 1856. Disponível em: <http://www-apps.crl.edu/brazil/almanak>. Acesso em: 16 nov. 2020. 
A educação de surdos no Brasil no século XIX e o legado de países europeus

ALMANAK do Amigo dos Surdos-Mudos. Rio de Janeiro: Typographia de Pinheiro e \& C., 1888.

ALVES, Maria do Céu Garcia dos Reis Loureiro. Educação especial e modernização escolar: estudo histórico-pedagógico da educação de surdos-mudos e de cegos. 2012, 49 lf (Tese de Doutorado) - Instituto de Educação, Universidade de Lisboa, 2012.

ARANHA, Maria Lucia de Arruda. História da educação. São Paulo: Editora Moderna, 1996.

BENVENUTO, Andrea; SÉGUILLON, Didier. Primeiros banquetes dos surdos-mudos no surgimento do esporte silencioso 1834-1924: por uma história política das mobilizações coletivas dos surdos. Revista Moara, n. 45, p. 60-78, jan./ jun. 2016.

BERTHIER, Ferdinand. O Abade Sicard: célebre professor de surdos mudos sucessor imediato do Abade de L'Épée. In: CARVAlHO, Paulo Vaz de. A Herança do Abade de L'Épée na viragem do século XVIII para o século XIX. Lisboa: The Factory, 2013.

BRASIL. [Constituição ( 1 824)]. Constituição Política do Império do Brasil: elaborada por um Conselho de Estado e outorgada pelo Imperador D. Pedro I, em 25.03.1824. Disponível em: http://www.planalto.gov.br/ccivil_03/Constituicao/Constituicao24.htm. Acesso em:

BRASIL. Decreto $\mathbf{n}^{\circ}$ 1.331-A, de 17 de fevereiro de 1854. Approva o Regulamento para a reforma do ensino primario e secundario do Municipio da Côrte. Disponível em: https:// www2.camara.leg. br/legin/fed/decret/1824-1899/decreto-1 33 1-a-17-fevereiro-1854-590 146-publicacaooriginal-1 15292-pe.html. Acesso em: 15 jun. 2020.

BORG. Per Aron. Projecto para o Regulamento do Real Instituto dos Surdos-Mudos e Cegos em Portugal. Lisboa: B. Rademake, 1824.

CARVAlHO, Paulo Vaz de. História dos Surdos I: no mundo e em Portugal. Lisboa: Universidade Católica Editora, 2007.

CARVAlHO, Paulo Vaz de. História da Educação dos Surdos II. Lisboa: Universidade Católica Editora, 2011.

CARVALHO, Paulo Vaz de. A herança do Abade de L'Épée na viragem do século XVIII para o século XIX. Lisboa: The Factory, 2013.

CARVALHO, Paulo Vaz de. História da educação de surdos: o que dizem as fontes documentais. Medi@ções. Revista Online da Escola Superior de Educação do Instituto Politécnico, Setúbal, v. 7, n. 1, p. 101-110, 2019. 
COELHO, Orquídea; CABRAL, Eduardo; GOMES, Maria do Céu. Formação de surdos: ao encontro da legitimidade perdida. Educação, Sociedade \& Culturas, Porto, v. 22, p. 153$181,2004$.

CUNHA, José Crispim da. História do Instituto dos Surdos-Mudos e Cegos de Lisboa desde a sua fundação até a sua incorporação na Casa Pia. Lisboa: Typographia de Filippe Nery, 1835.

DETIENNE, Marcel. Comparar o incomparável. São Paulo: Ideias e Letras, 2004.

DEUTOUR, Félix. L'institution Nationale des Sourds-Muets de Paris. Revue des Deux Mondes, Paris, v. 111 , p. 174-207, maio/juin. 1892.

DU CAMP, Maxime. L'Enseignement exceptionnel à Paris. Revue des Deux Mondes. Bureau de la Revue des Deux Mondes, v. 104, p. 555-577, jan./fév. 1873.

FONSECA, Maria Rachel Fróes da. Dicionário Histórico-Biográfico das Ciências da Saúde no Brasil (1 832-1930). Disponível em: http://www.dichistoriasaude.coc.fiocruz.br/iah/ pt/verbetes/collnacsur\#topo Acesso em: $1^{\circ}$ jun. 2020.

GIL, Antônio Carlos. Como elaborar projetos de pesquisa. São Paulo: Atlas, 2002.

GONDRA, José. Artes de civilizar. Medicina, higiene e educação na corte imperial. Rio de Janeiro: EDuERJ, 2004.

IBGE, Recenseamento do Brazil em 1872. Rio de Janeiro: Typographia G. Leuzinger, [1875].

LEITE, Tobias Rabello. Instituto dos Surdos-Mudos. Relatório do Diretor. Apresentado em março de 1869. Rio de Janeiro: Typografia Nacional, 1868.

LEITE, Tobias Rabello. Instituto dos Surdos-Mudos. Relatório do Diretor. Apresentado em março de 1870. Rio de Janeiro: Typografia Nacional, 1870.

LEITE, Tobias Rabello. Instituto dos Surdos-Mudos. Relatório do Diretor. Apresentado em 26 de fevereiro de 1872. Rio de Janeiro: Typografia Nacional, 1872.

LEITE, Tobias Rabello. Instituto dos Surdos-Mudos. Relatório do Diretor. Apresentado em 31 de março de 1874. Rio de Janeiro: Typografia Nacional, 1874.

MARSON, Adalberto. Reflexões sobre o procedimento histórico. In: SILVA, Marco Antônio da (org.). Repensando a história. Rio de Janeiro: Marco Zero, 1984. 
MARTINEZ, Alessandra Frota. Educar e instruir: a instrução popular na Corte Imperial - 1870 a 1889. 1997. 300f. Dissertação (Mestrado em História) - Programa de PósGraduação em História, Universidade Federal Fluminense, Niterói, 1997.

MARTINS, Ernesto Candeias. Educação (especial), métodos de ensino e instituições destinadas à surdez em Portugal: visão sociohistórica no séc. XIX e inícios do XX. Revista Temas em Educação, João Pessoa, v. 29, n. 2, p. 96-118, maio/ago. 2020.

OlIVEIRA, João Alfredo Correa de. Relatorio Apresentado a Assembléa Geral. Rio de Janeiro: Typographia Universal, 1872.

RIBEIRO, Maximina Maria Girão da Cunha. Resgatados do silêncio - surdez e pedagogia: o Instituto Araújo Porto (1 893-1945). Lisboa: Almedina, 2018.

ROCHA, Solange. O INES e a educação de surdos no Brasil: aspectos da trajetória do Instituto Nacional de Educação de Surdos em seu percurso de 150 anos. Rio de Janeiro: INES, 2007.

SAVIANI, Dermeval. O legado educacional do "breve" século XIX brasileiro In: SAVIANI, Dermeval; ALMEIDA, Jane Soares de; SOUZA, Rosa Fátima de; VALDEMARIN, Vera Teresa. Campinas, Autores Associados, 2014.

24 SÉGUILLON, Didier. A corps et à cri. Editions EPS, n. 252, p. 32-34, mar./abr. 1995.

SCHUELER, Alessandra Frota Martinez de. Crianças e escolas na passagem do Império para a República. Revista Brasileira de História, São Paulo, v. 19, n. 37, set. 1999.

SILVA, Indiana Azeredo; CASTANHA, André Paulo. Educação dos surdos no Brasil entre 1856 e 1911. Revista Faz Ciência, Cascavel, v. 17, n. 26, p. 169-186, jul./dez. 2015.

SOFIATO Cássia Geciauskas. A educação de surdos no século XIX: currículo prescrito e modelo de educação. Cadernos de Pesquisa, São Luís, v. 25, n. 2, abr./jun. 2018.

SOUZA, Verônica dos Reis Mariano. A educação dos surdos no século XIX. Revista Tempos e Espaços em Educação, Sergipe, v. 1, p. 49-56, jul./dez. 2008.

VIRENQUE, Hélène. La communauté sourde en France au XIX e siècle: entre langue des signes et oralisme. 2017. Disponível em: https://gallica.bnf.fr/blog/23092017/la-communaute-sourde-en-france-au-xixe-siecle-entre-langue-des-signes-et-oralisme? mode=desktop. Acesso em: 12 out. 2020. 
Profa. Dra. Cássia Geciauskas Sofiato

Universidade de São Paulo (Brasil) Programa de Pós-graduação em Educação

Orcid id: 0000-000 1-5291-9658 E-mail: cassiasofiato@usp.br

Prof. Dr. Paulo Vaz de Carvalho Universidade Católica Portuguesa (Portugal) Programa de Pós-graduação: Investigador integrado no Centro de Investigação Interdisciplinar em Saúde Orcid id: 0000-000 1-5345-3896 E-mail: pcjanas.vazdecarvalho@gmail.com

Profa. Dra. Orquídea Coelho Universidade do Porto (Portugal) Programa de Pós-graduação: Investigadora do Centro de Investigação e Intervenção Educativas Orcid id: 0000-000 1-78 19-7956 E-mail: orquidea@fpce.up.pt

Recebido 30 out. 2020 Aceito 12 nov. 2020 